\title{
Traduzir e ser traduzido. Notas sobre discurso e migrações
}

To Translate and Be Translated. Notes on Discourse and Migrations

Traduire et être traduit. Notes sur le discours et les migrations

\section{António Sousa Ribeiro}

\section{CpenEdition}

\section{Journals}

Edição electrónica

URL: http://journals.openedition.org/rccs/7663

DOI: $10.4000 /$ rccs.7663

ISSN: 2182-7435

\section{Editora}

Centro de Estudos Sociais da Universidade de Coimbra

Edição impressa

Data de publição: 7 Novembro 2018

Paginação: 55-70

ISSN: 0254-1106

Refêrencia eletrónica

António Sousa Ribeiro, "Traduzir e ser traduzido. Notas sobre discurso e migrações », Revista Crítica de Ciências Sociais [Online], Número especial | 2018, colocado online no dia 05 novembro 2018, criado a 01 maio 2019. URL : http://journals.openedition.org/rccs/7663 ; DOI : 10.4000/rccs.7663 


\section{ANTÓNIO SOUSA RIBEIRO}

\section{Traduzir e ser traduzido. Notas sobre discurso e migrações*}

Neste artigo percorrem-se alguns aspectos da relação entre discurso e migrações, sublinhando-se a persistência na Europa contemporânea de regimes de representação de raiz colonial e definindo-se os vectores essenciais de uma ética e política da tradução susceptíveis de proporcionar os fundamentos de uma lógica de inter-reconhecimento.

Palavras-chave: colonialidade; discurso; migrações; refugiados; tradução.

A cena passa-se num fim de tarde em Viena, há cerca de 20 anos, no âmbito de uma conferência pública a cargo da reputada sociolinguista Ruth Wodak, a que tive oportunidade de assistir. Estava reunida uma apreciável massa de gente, de várias centenas de pessoas, já que a conferência, incluída nas chamadas Conferências Vienenses, uma série de sessões para o grande público organizadas pela municipalidade, tinha lugar no imenso salão nobre da Câmara Municipal da capital austríaca. Ruth Wodak estava, no fundamental, a apresentar os resultados dos seus projectos de investigação sobre a construção discursiva da identidade austríaca (Wodak et al., 1998). Na parte final da sessão, houve o período habitual de perguntas e respostas. Tudo corria em perfeita normalidade, até ao momento em que um membro do público fez a pergunta: "Considera que os imigrantes que pretendam obter a nacionalidade austríaca devem ser obrigados a fazer prova de domínio fluente da língua alemã?”. A resposta, lacónica, veio de rajada, sem a mínima hesitação: "Não, não considero".

Enquanto observador e estrangeiro, o tumulto entre a assistência e a atmosfera agressiva que, de imediato, se geraram, deixaram-me atónito. Indubitavelmente, a resposta à pergunta tocara um nervo muito sensível. Um cavalheiro já de idade, que parecia particularmente indignado, fez questão

* Por vontade do autor, este artigo não segue as regras do Acordo Ortográfico de 1990. 
de citar alguns versos do poeta nacional austríaco, Franz Grillparzer, indispensáveis nas cartilhas escolares, sobre o valor da língua alemã para a definição da nação austríaca, assim tornando perfeitamente claro que a origem da agitação geral estava na equação, pelos vistos, profundamente radicada entre um largo sector dos presentes entre a pertença nacional e a partilha de uma língua nacional e na desconfiança, não menos enraizada, contra toda a transgressão de um conceito de assimilação assente nos termos definidos pela lógica dominante da nação.

Evidentemente que Ruth Wodak não estava a negar minimamente o valor e importância do domínio da língua para quem decide viver e trabalhar num país que não é o seu. Estava, contudo, a criticar duramente o que, a seu ver, era o estabelecimento de um requisito jurídico que representava a negação de valores e direitos humanos fundamentais. Num ensaio posterior, ela escreveria, com verve polémica, que os testes de língua se transformaram em "novos guardas fronteiriços (pós)modernos", funcionando como "uma espécie de bilhete de admissão à Terra Prometida” (Wodak, 2013: 10). ${ }^{1}$ E, num capítulo recente, Wodak insiste em recordar que, em oposição a uma noção de cosmopolitismo ou pós-nacionalismo como marcas de uma cidadania europeia, "o conceito de 'língua materna" e o "regresso a políticas nacionais de língua que essencializam o Estado-nação, projectando uma cultura, língua e território homogéneos [...] está relacionado com 'políticas do corpo' nativistas que vêem e conceptualizam a nação como um corpo, com a língua materna a simbolizar a língua nacional” (Wodak, 2018: 410-411).

Havia, no entanto, um outro aspecto importante que Ruth Wodak certamente queria sublinhar ao recusar-se a satisfazer as expectativas de um largo sector do público naquele fim de tarde em Viena: estava, também, a salientar, implicitamente, que o domínio da língua de modo nenhum iria permitir superar automaticamente a miríade de outros factores de discriminação presentes na sociedade austríaca, como noutras sociedades europeias, contra imigrantes de diferentes proveniências. Por outras palavras, estava a apontar para o facto de que ser, literalmente, traduzido implicava problemas muito mais profundos, que uma simples exigência de assimilação através da língua era incapaz de resolver.

Veio-me à ideia este significativo episódio no contexto de uma reflexão sobre a relevância do conceito de tradução para as questões atinentes à relação entre discurso e migrações. Tratou-se, efectivamente, de um momento em que se me tornou dolorosamente claro em que medida uma concepção mítica de língua nacional estava a funcionar, naquele contexto específico, como um operador

\footnotetext{
1 Todas as traduções são do autor.
} 
poderoso para o confronto com aquilo a que, numa obra recente, Reece Jones chamou o "complexo da invasão" (Jones, 2016). A prova de proficiência linguística não bastaria, claramente, por si só, para garantir a integração na sociedade austríaca. Contudo, no imaginário colectivo, esta exigência parecia, de alguma forma, oferecer uma sensação de segurança, uma possibilidade de controlar o medo do heterogéneo - como signo de unidade, a língua nacional proporcionaria a ilusão de uma fronteira bem definida, cuidadosamente acautelada, a delimitar um território essencialmente seguro.

Desde o final do milénio, a escala e natureza das mobilidades forçadas transformaram-se drasticamente, em particular na sequência da equivocamente chamada "crise dos refugiados". Uma consequência não menor deste processo foi, seguramente, a desestabilização do sentido das próprias palavras "refugiado" e "migrante". Como é sabido, a Convenção sobre os Refugiados das Nações Unidas, ${ }^{2}$ proclamada em 1951, oferecia uma definição muito restrita, uma vez que conferia aos países signatários a liberdade para optar por uma definição de refugiado como vítima dos "acontecimentos ocorridos na Europa antes de 1 de Janeiro de 1951", restringindo, assim, no fundamental, o âmbito do conceito às consequências do Nazismo e da Segunda Guerra Mundial em solo europeu. A Convenção foi revista em 1967 para eliminar as limitações geográficas e as balizas temporais. No entanto, a definição da condição de refugiado como sendo aplicável a quem teve de abandonar o país de origem "devido ao receio fundado de ser perseguido por motivos relacionados com a raça, religião, nacionalidade, pertença a um grupo social ou a uma opinião política determinada", em oposição ao migrante, que, supostamente, se deslocou voluntariamente para um outro país, tende a obscurecer o simples facto de que migrantes que se deslocam por motivos económicos ou ligados a questões ambientais o fazem, em muitos casos, não por escolha, mas porque, por uma série de razões, incluindo a exploração desenfreada de recursos naturais por grandes empresas multinacionais, as condições de vida no local de origem se tornaram insuportáveis ou fazem mesmo incorrer em risco de vida.

Embora a escala dificilmente tenha precedentes, questões fundamentais suscitadas pela situação presente não são novas e têm de ser entendidas na longa duração das relações entre a Europa e os seus "outros". Neste aspecto, chama particularmente a atenção a inexistência, em geral, de uma consciência aprofundada do modo como a definição da diferença e a percepção da diferença permanece, no discurso europeu, presa a um quadro de referência

\footnotetext{
${ }^{2}$ Os textos da Convenção de 1951 e do protocolo de 1967 que revê a versão inicial são facilmente acessíveis (por exemplo, em http://www.unhcr.org/3b66c2aa10, consultado a 07.05.2018). Para uma intervenção muito recente sobre o conceito de "refugiado climático", ver Pedra (2018).
} 
informado pela persistência daquilo a que Pascal Blanchard chamou la fracture coloniale [a fractura colonial] (Blanchard et al., 2005). Esta fractura está sobredeterminada por uma longa história de exclusão violenta - as formas muito diversas em que essa memória reverbera na percepção de hoje mereceriam muito mais atenção do que aquela que têm recebido. Tendo em mente a memória da Guerra da Argélia em França, Benjamin Stora põe em relevo aquilo a que chama transferts de mémoire [transferências de memória], que implicam que uma imagem do "inimigo" consolidada no contexto da guerra seja persistentemente projectada sobre migrantes provenientes do Norte de África e, em geral, sobre a larga população francesa de religião muçulmana (Stora, 1999). Novas formas de diferenciação e exclusão, especialmente marcadas por preconceitos anti-árabes, alimentam-se de uma história de violência estreitamente associada ao passado colonial europeu, razão pela qual as lutas pela memória permanecem um elemento tão decisivo na constituição de uma esfera pública europeia democrática e cosmopolita.

Seja no plano da recuperação de uma perspectiva nação-cêntrica, seja do ponto de vista de uma concepção cristalizada do "Ocidente", as fantasias de centralidade continuam a desempenhar um papel fundamental. Num dos textos fundadores da União Europeia, a declaração de Robert Schuman de 9 de Maio de 1950 propondo o chamado Plano Schuman, consta uma referência quase de passagem que pode facilmente passar despercebida, mas é muito esclarecedora neste aspecto: o desenvolvimento económico europeu permitiria que a Europa levasse a cabo "uma das suas tarefas fundamentais, o desenvolvimento do continente africano" . N Naturalmente que, à época, a inevitável e iminente provincialização da Europa (Chakrabarty, 2000) estava inteiramente fora do horizonte dos políticos europeus. No quadro de uma redefinição da "ideia europeia" no período imediatamente a seguir à Segunda Guerra Mundial, é evidente que a fantasia de centralidade implícita na alusão de Schuman, enquanto versão moderna, consciente ou inconsciente, do "fardo do homem branco", se baseava no facto do domínio colonial europeu sobre largas parcelas do continente africano. Mas a mesma ideia de Europa permanece, até aos nossos dias, ferida de contradições e heterogeneidades que são inseparáveis da constituição simbólica de padrões sólidos de identidade que se projectam sobre outros países ou regiões europeus na forma de estereótipos distintamente informados pela diferença colonial. Assim, quando, em 17 de Maio de 2011, Angela Merkel exigia que os europeus do Sul deveriam ter menos feriados e reformar-se mais tarde, isto é, trabalhar

\footnotetext{
${ }_{3}$ Pode ler-se o texto da Declaração, por exemplo, em https://www.robert-schuman.eu/en/doc/ questions-d-europe/qe-204-en.pdf (consultado a 07.05.2018).
} 
mais duramente como, supostamente, fazem os europeus do Norte, não se tratava apenas da demonstração do poder de estereótipos que, como hoje é muito claro, desempenharam, com consequências pesadas, um papel não despiciendo na resposta dilatória e insuficiente à crise financeira, esses mesmos estereótipos evidenciam claramente a projecção de uma imagem do Sul da Europa moldada a partir da diferença colonial (Ervedosa, 2017).

Uma tal projecção tem uma longa tradição. $\mathrm{Na}$ sua obra Imagining the Balkans, Maria Todorova, partindo das teses de Edward Said sobre o Orientalismo, define o balcanismo como uma formação discursiva que projecta a imagem puramente negativa, quando não pejorativa, de uma semiexistência: na imaginação europeia dominante, os Balcãs, escreve Todorova, são "semidesenvolvidos, semicoloniais, semicivilizados, semiorientais" (1997: 16). Analogamente, no ensaio, hoje clássico, "Entre Prospero e Caliban" (Santos, 2002), Boaventura de Sousa Santos mostra, à luz de abundantes exemplos, como a fantasia nacional portuguesa da ocupação de uma posição central como Prospero colonizador contrasta com visões norte-europeias que fixam os portugueses no papel de um Caliban incivilizado. Os exemplos citados por Santos, e muitos outros poderiam acrescentar-se, abundam, por exemplo, em alusões à horrenda fealdade dos portugueses, enquanto mistura de raças tidas como inferiores, e incidem em tópicos como a pouca disponibilidade para o trabalho, a incapacidade de explorar devidamente os recursos naturais do país de uma forma racional ou a imoralidade e promiscuidade de gente incapaz de controlar as suas pulsões sexuais de forma civilizada - tudo lugares comuns rotineiramente aplicados pelo discurso colonial aos povos colonizados.

A degradação discursiva do Sul está em consonância com a persistência, e mesmo o reforço, de um modelo centro-periferia que reproduz no plano intra-europeu uma geografia simbólica do poder análoga, de muitas maneiras, aos estereótipos da diferença colonial. Estes estereótipos, mesmo que em forma mais sofisticada, ocorrem em contextos muitas vezes inesperados. Veja-se, por exemplo, a expressão Kerneuropa, no sentido de "o núcleo da Europa" ou "os países nucleares europeus". A expressão foi introduzida no discurso europeu através do documento "Ideias sobre a política europeia" ["Überlegungen zur europäischen Politik”], o chamado documento Schäuble-Lamers, da autoria dos políticos cristãos-democratas alemães Wolfgang Schäuble e Karl Lamers. Foi, depois, usada, entre outros, pelo então ministro dos Negócios Estrangeiros da Alemanha, Joschka Fischer e, pouco mais tarde, emergiria num lugar central, o apelo conjunto lançado, em 2003, por Jürgen Habermas e Jacques Derrida na sequência da invasão do Iraque, publicado na Alemanha pelo influente jornal Frankfurter Allgemeine Zeitung com o título "Unsere Erneuerung. Nach dem Krieg: die Wiedergeburt Europas” [“A nossa renovação. Depois da guerra: 
o renascimento da Europa] (Habermas e Derrida, 2003a). ${ }^{4} \mathrm{O}$ manifesto é um apelo à unidade que, aos olhos dos autores, só pode ser promovida "se os estados-membros nucleares" forem capazes de iniciativa e de conduzir um processo de reflexão no curso da qual, no contexto da "incomparavelmente rica diversidade" da Europa contemporânea, "os cidadãos de uma nação têm de considerar os cidadãos de uma outra nação como, fundamentalmente, "um de nós" (ibidem). O que chama a atenção, por um lado, é o facto de o ímpeto utópico, sem dúvida, bem intencionado, do manifesto assentar num conceito, o de "núcleo europeu", fundado numa relação de poder assimétrica e marcado pela definição de uma fronteira aparentemente intransponível; por outro lado, apesar de um apelo final à rejeição do eurocentrismo, o modelo, proposto pelo documento, de uma relação com o outro como "reconhecimento recíproco do outro na sua alteridade" e como a base de uma possível "identidade comum" futura, não apenas permanece inteiramente abstracto como, sobretudo, focando-se nas relações entre os países europeus, esquece o facto de que a história da Europa e da constituição da Europa teve lugar, em aspectos fundamentais, fora das fronteiras geográficas do continente europeu.

"A Europa contemporânea", escrevem os autores, "foi moldada pela experiência dos regimes totalitários do século xx e pelo Holocausto" (ibidem). Apenas no breve final se encontra uma referência ao passado colonial europeu:

Cada uma das grandes nações europeias viveu o apogeu do seu poder imperial e [...] teve de lidar com a experiência da perda de um império. [...] Com a distância crescente relativamente ao domínio imperial e à história do colonialismo, as potências europeias ganharam a possibilidade de assumir uma distância reflexiva em relação a si próprias [...] de se verem no papel dúbio de vencedores a quem se exige que prestem contas pela violência de uma modernidade imposta e desenraizadora. (Habermas e Derrida, 2003a)

Limitar a questão do colonialismo simplesmente à dinâmica de uma "modernidade imposta e desenraizadora" tem um desagradável ressaibo a eufemismo. Mas, independentemente disso, a questão central, a meu ver, está em que a presença contemporânea do migrante e do refugiado, da enorme massa de gente a bater à porta da Europa, põe inteiramente em questão a ideia da distância crescente relativamente à história do colonialismo. Na realidade, em muitos aspectos, o colonialismo tem de ser visto como um elemento definidor, não apenas do passado, mas da contemporaneidade europeia, e,

\footnotetext{
${ }^{4}$ Uma versão em língua inglesa foi publicada quase em simultâneo na revista Constellations (Habermas e Derrida, 2003b).
} 
ao não enfrentar esta questão, o manifesto de Habermas e Derrida vem, no fim de contas, ocupar um lugar no seio da tradição de um discurso utópico europeu em que a celebração da diversidade cultural só insuficientemente reflecte sobre a natureza conflitual e o potencial de violência de uma definição da diferença que percorre aquilo a que Boaventura de Sousa Santos chamou a linha abissal enquanto traço definidor da diferença colonial (Santos, 2007).

Reconhecer que a fractura colonial não pertence simplesmente ao passado da Europa, mas sim ao seu presente, tem várias consequências decisivas. A mais importante será, sem dúvida o reconhecimento da prevalência do racismo nas sociedades europeias. Para regressar às minhas referências iniciais sobre a questão da linguagem, a pesquisa etnográfica entre comunidades migrantes em Portugal, mas também a observação corrente, não têm dificuldades em identificar casos de discriminação racista baseados na língua: é bem sabido que um sotaque africano ao telefone pode facilmente custar a perda de uma oportunidade de emprego ou da possibilidade do arrendamento de uma casa. A organização SOS Racismo reporta, sistematicamente, situações no local de trabalho em que, por exemplo, funcionários que estão a conversar em crioulo cabo-verdiano são proibidos pela gerência de o fazer. Há cerca de dois anos, na Áustria, verificou-se um debate sobre uma iniciativa do governo da Alta Áustria de acordo com a qual as crianças de escola deveriam ser proibidas de usar, em contexto escolar, qualquer língua que não o alemão, incluindo durante o recreio no pátio. A iniciativa foi bloqueada pelos órgãos federais, mas o simples facto de que um tal absurdo possa ter sido tomado seriamente em consideração é muito revelador. ${ }^{5}$ Portugal ocupa, sistematicamente, em inquéritos internacionais como, por exemplo, o European Social Survey, uma posição pouco lisonjeira no respeitante ao tópico do racismo. A prevalência da discriminação racista - não apenas o ressentimento anti-refugiado ou anti-imigrante, na dimensão alarmante que tem vindo a assumir em muitos países europeus, mas as formas de discriminação quotidianas que, muitas vezes, se manifestam a uma microescala - mostra à saciedade em que

\footnotetext{
${ }^{5}$ Sobre este caso, ver "Deutschpflicht in Schulen: Bund erteilt Wünschen aus Oberösterreich Absage", Standard, 5 de setembro de 2016. A sociolinguística austríaca, a começar pelos trabalhos já referidos de Ruth Wodak, tem dado contributos muito relevantes para a discussão da relação entre língua e migração. Uma das percepções mais importantes, aparentemente elementar, mas inteiramente estranha ao senso comum nacional, vem lapidarmente expressa na tomada de posição, em 2011, do Grupo de Investigação Interuniversitário 'Língua, Migração e Crítica ao Racismo': “Turco, bósnio-croata-sérvio ou polaco não são línguas estrangeiras na Âustria. A não ser que se queira, de uma penada, declarar que uma parte da população austríaca é estrangeira e, assim, é uma não-população" (itálico no original; cf. "Bildung und die österreichische Migrationsgesellschaft. Einladung zu Entdramatisierung und Versachlichung", acessível em https://www.uibk.ac.at/iezw/archive/copy_of_einmischungen/texte/ stellungnahme-ag-sprache-migration-und-rassismuskritik.pdf, consultado a 23.07.2018).
} 
medida a integração ou a assimilação não são sempre senão uma condição provisória: independentemente da cidadania formal, quem, pelos mais diferentes motivos, desde a cor da pele à língua, transporte sinais de alteridade, está sujeito a que, em contextos determinados, esses sinais sejam activados como marca de exclusão e surjam como legitimação de práticas da violência.

Estas observações conduzem à questão central que tem de ser posta em equação por qualquer abordagem crítica da relação entre discurso e migração, a questão da tradução. A imagem mais corrente para os processos de tradução é a imagem da ponte. Demasiadas vezes, no entanto, esta imagem surge, tanto no discurso corrente, como no discurso da política ou da academia, como a solução, e não como a formulação de um problema. De facto, é manifesto que, se é necessária uma ponte, é porque existe um obstáculo a transpor. Esta é, evidentemente, a questão central: a ponte tem de ser tomada, não como alguma coisa que permite negligenciar e fazer esquecer o obstáculo transposto, mas sim como algo que torna manifesta a existência e persistência desse obstáculo. É assim que qualquer conceito de tradução tem de ser fundado numa noção de conflito: como as línguas e culturas são, por definição, incomensuráveis, toda a teoria da tradução tem de começar por se confrontar com o problema da intraduzibilidade. Por outras palavras, todo o processo de tradução mais não é do que o esforço para superar este problema, através da procura de uma medida comum que permita compreender e pôr em relação o que é irrevogavelmente diferente. Toda a solução neste âmbito, como todo o tradutor sabe ou devia saber, é sempre precária e, de certa forma, provisória: não há universais da tradução, uma vez que, em última análise, tudo está dependente da particularidade do contexto de uma língua e cultura determinadas. ${ }^{6}$

Fundamentar o conceito de tradução numa noção de intraduzibilidade não pode, no entanto, ser confundido com modelos da relação intercultural que postulam a não-tradução ou a recusa de traduzir como a base defensiva de uma identidade potencialmente agressiva. O mais influente desses modelos será, seguramente, o do "choque de civilizações" proposto por Samuel Huntington (1996), que representa uma versão extrema daquilo a que um crítico chamou uma "insânia de identidade" (Meyer, 1997), com o seu postulado do carácter estanque das esferas culturais que, no melhor dos casos, podem apenas coexistir e, no pior, se relacionam entre si através do conflito e da guerra (recorde-se como, na mais perfeita ortodoxia schmittiana, para Huntington, só é possível conhecer verdadeiramente a própria identidade

\footnotetext{
${ }^{6}$ Sobre a questão da intraduzibilidade, veja-se, entre outros, Budick e Iser (1996); Cassin (2004); Levine e Lateef-Jan (2018); Large et al. (2018).
} 
a partir do momento em que foi possível identificar o inimigo). ${ }^{7}$ Nos termos que estou a propor, a noção de intraduzibilidade permite não perder nunca de vista que a tarefa da tradução - tornar inteligível a diferença e produzir um espaço comum para o relacionamento com a diferença - não significa um processo de assimilação. Kwame Anthony Appiah propõe o conceito de "tradução densa" para abranger os processos de tradução que incorporam a percepção da forma como rituais e práticas, incluindo as práticas discursivas, estão enraizados em contextos culturais complexos (Appiah, 1993). Em anos recentes, o conceito de tradução cultural tornou-se corrente, como chamada de atenção para o facto de que toda a relação entre textos escritos em línguas diferentes é uma relação entre culturas diferentes. ${ }^{8}$ Isto, porém, não é bastante, já que o próprio conceito de cultura está envolvido em considerável turbulência. Na formulação famosa de James Clifford, “as 'culturas' não ficam quietas à espera da fotografia” (1986: 10). Por outras palavras, as culturas são processos dinâmicos e conflituais e não simplesmente cânones estabelecidos ou repertórios estáveis. Por esta razão, neste mesmo sentido, Stuart Hall (1992) escreveria, nos anos 90, que a cultura é mais uma questão de tradução do que de tradição, com a implicação de que estar-em-tradução não é um traço incidental, mas uma característica essencial, definidora, de qualquer cultura.

Num breve artigo escrito no início dos anos 90, Wolfgang Iser recordava que a "traduzibilidade" implica "a tradução da alteridade sem submeter esta a noções pré-concebidas” (Iser, 1994). Isto é, continuando a citar Iser, no acto de tradução, "uma cultura estranha não é simplesmente subsumida ao nosso quadro de referência; é esse mesmo quadro que é sujeito a transformações para integrar aquilo que não se ajusta" (ibidem). É esta a questão fundamental, que nos remete de novo para a questão, atrás, aflorada, da intraduzibilidade. Se cada acto de tradução, enquanto refutação prática da impossibilidade de traduzir, corresponde a pôr em questão e redefinir um quadro de referência estabelecido, então, do mesmo passo, o que está a ser posto em questão e redefinido são também as relações de poder entre as culturas. $\mathrm{O}$ acto de subsumir, de assimilar, como Adorno repetidamente insistiu, corresponde a exercer poder no domínio conceptual. No âmbito da teoria pós-colonial, o conceito de colonialidade, proposto por Aníbal Quijano (1997), visa, justamente, o processo de submissão do alegadamente

\footnotetext{
7 "Só sabemos quem somos quando sabemos quem não somos e, muitas vezes, quando sabemos contra quem somos” (Huntington, 1996: 21).

${ }^{8}$ Para uma introdução ao conceito de tradução cultural pode ver-se Maitland (2017); veja-se também Buden et al. (2009). A revista Translation Studies dedicou vários dos seus números posteriores à discussão do conceito.
} 
subalterno a análogas lógicas de poder, desde logo no plano simbólico, muito para além do fim das relações formais de colonização. ${ }^{9}$ É por essa razão que um conceito de tradução resultante da crítica das epistemologias coloniais tem de se distanciar da ideia de um diálogo entre culturas representado pela imagem da ponte. Ao implicar, necessariamente, a negociação de diferenças, a tradução não se esgota, efectivamente, num conceito de diálogo. Na verdade, o conceito de alteridade é inseparável dos processos de tradução que permitem o relacionamento com essa alteridade - o espaço da fronteira, que constitui esse espaço de negociação é, por definição, precário e instável, quer dizer, é sempre um espaço de contingência em que a presença do não-idêntico põe permanentemente em causa qualquer noção de síntese e de assimilação, mantendo, pelo contrário, operativa uma relação de tensão e estranheza mútuas. É assim que, se a razão da tradução é uma razão cosmopolita, é-o, não na medida em que possa ir além das fronteiras, mas sim em que seja capaz de se situar na fronteira, de se instituir como razão fronteiriça, isto é, de ocupar os espaços de articulação e de negociar em permanência as condições dessa articulação. Só assim o efeito mais elementar da fronteira, a percepção de que existe um outro, pode traduzir-se na criação de condições de inteligibilidade que permitam superar a condição do intraduzível e produzir novas configurações insuspeitadas.

Neste aspecto, um elemento fundamental do potencial político do conceito de tradução reside na forma como ele se revela essencial para a definição de qualquer política do reconhecimento. Não é de mais, neste contexto, sublinhar a diferença irredutível entre reconhecimento e tolerância. A tolerância é um acto de poder que não tem sequer de traduzir qualquer esforço de aproximação relativamente ao que é tolerado. O reconhecimento, pelo contrário, pressupõe um envolvimento concreto com a diferença e a procura de modos de articulação com essa diferença. ${ }^{10}$ Por outras palavras, a tolerância é equivalente à recusa da tradução, ao passo que o reconhecimento só pode fundar-se em processos de tradução. A relevância desta questão tornou-se tragicamente evidente com a irrupção da chamada crise dos refugiados e as vagas maciças de migração pelo Mediterrâneo. Migrantes e refugiados são pessoas traduzidas, no sentido literal, foram projectados violentamente para contextos estranhos onde são forçadas a enfrentar a

\footnotetext{
${ }_{9}$ Para alguns exemplos particularmente chocantes da prevalência da lógica de colonialidade em processos de tradução, ver Venuti (1998). Para um desenvolvimento de algumas destas questões, ver Ribeiro (2005).

${ }^{10}$ Sobre o conceito de tolerância, pode ver-se a síntese crítica de Rainer Forst (2013). Cf. também Ribeiro (2004). O conceito de reconhecimento deve muito, como é sabido, aos trabalhos de Axel Honneth (entre muitas outras referências, ver Honneth, 2004).
} 
necessidade, não apenas de ser aceites, mas também de serem reconhecidas, isto é, de se tornarem sujeitos, e não apenas objectos, de tradução. Não obstante, os discursos correntes sobre migrantes e refugiados tendem a remetê-los para o outro lado daquela "linha abissal" cuja característica mais determinante, segundo Boaventura de Sousa Santos, está na "impossibilidade da co-presença dos dois lados da linha" (Santos, 2007: 4). No seu ensaio "We Refugees", de 1943, Hannah Arendt concluía a sua reflexão autobiográfica sobre a condição do refugiado escrevendo que "a comunidade dos povos da Europa fez-se em pedaços quando permitiu, e porque permitiu, que o seu membro mais fraco fosse excluído e perseguido" (Arendt, 1994 [1943]: 119). A questão, no contexto europeu contemporâneo, é o facto de o refugiado nunca ter sido sequer reconhecido como "membro", podendo, assim, ser excluído sem mais de forma burocrática e rotineira. Isto é concomitante com o que Zygmunt Bauman caracteriza como "a constrição do domínio de obrigações morais que estamos dispostos a admitir, pelas quais estamos dispostos a responsabilizar-nos e que estamos dispostos a aceitar como objecto da nossa atenção constante, diária, e da nossa acção correctiva" (Bauman, 2016: 135). O que significa que os migrantes e refugiados estão permanentemente a ser empurrados para além da "zona de tradução", ${ }^{11}$ isto é, empurrados para um não-território em que o reconhecimento dos seus direitos humanos está suspenso. As fronteiras tornaram-se flexíveis, passam por sítios insuspeitados e definem espaços de exclusão, não-espaços, em que o outro é construído como "intraduzível", isto é, como alguém fechado numa irredutível estranheza e que formula reivindicações ou exprime necessidades que não poderiam ser satisfeitas sem prejuízo irreparável para a comunidade. Nestas circunstâncias, não pode haver tradução enquanto negociação de diferenças, mas tão-somente uma reacção defensiva baseada na erecção de fronteiras violentas entendidas como linhas abissais.

Neste quadro, a tarefa política e ética consistirá, em conformidade, em ampliar os limites da zona de tradução de modo a permitir abranger as muitas experiências diferentes e os diversos discursos que emergem nas condições actuais de mobilidade global. Ao lidar com um problema de tão grande escala, é importante, evidentemente, insistir numa medida comum de humanidade - é esse o fundamento da compaixão, entendida, não como uma emoção sentimental, mas sim como um modo cognitivo e performativo de relacionamento com as dificuldades do outro. Mas é igualmente importante perceber que essa humanidade comum fala muitas línguas diferentes,

${ }_{11}$ O conceito de "zona de tradução" deve-se a Emily Apter (2006), embora seja definido pela autora num sentido algo diferente do que aqui proponho. 
está dividida e fragmentada de acordo com miríades de diferentes linhas de fronteira que têm de ser reconhecidas na sua especificidade. Por outras palavras, nada se ganha em subestimar as dificuldades da comunicação intercultural, visto que o terreno comum do reconhecimento mútuo não é simplesmente pré-existente - proporcionado, por exemplo, por uma retórica universal de direitos humanos -, antes tem de ser reafirmado e produzido no próprio acto de tradução.

Para dar um exemplo entre muitos possíveis, a dificuldade de reconhecimento em contextos práticos está bem ilustrada no documentário La forteresse, do realizador suíço Fernand Melgar, ele próprio filho de um emigrante espanhol, produzido em 2008. ${ }^{12} \mathrm{O}$ documentário foca-se no quotidiano de um centro de detenção para requerentes do estatuto de refugiado numa pequena cidade suíça. Um dos aspectos mais impressivos do filme está na forma como aborda a questão do testemunho. Na verdade, em boa medida, a decisão de concessão, ou não, do direito de permanência depende da credibilidade do discurso que o candidato ou candidata consegue articular sobre a sua trajectória pessoal. O requerente ou a requerente está, desde o início, numa posição desvantajosa, não apenas pela debilidade física ou mental e pela necessidade, quase sempre, da mediação de um intérprete, mas também porque o testemunho que produz é sempre objecto de enorme suspeita, já que, na maior parte dos casos, não existem provas documentais ou outras que possam ser apresentadas, existe apenas a narrativa individual. A teoria do testemunho tem vindo a sublinhar a importância do envolvimento numa situação dialógica, que depende sempre do interlocutor, sobretudo quando do que se trata é de memórias traumáticas e a empatia com um ouvinte permite a quem está a produzir o testemunho quebrar um silêncio que pode ter pesado durante muito tempo ou trazer à linguagem experiências cujo extremo de violência as torna dificilmente verbalizáveis. Contudo, nas situações filmadas por Melgar, o interlocutor, mesmo quando não é abertamente hostil, é um representante do Estado e, em última análise, exerce funções quase de juiz, e a produção de testemunho tem, assim, lugar num quadro eminentemente desfavorável. Os funcionários que conduzem a entrevista estão colocados na posição de analistas do discurso, sem estarem necessariamente qualificados para tal: os critérios de verdade por que se norteiam dificilmente permitem fazer justiça à complexidade da dimensão performativa de uma situação em que o silêncio, o gesto, a linguagem corporal podem ser tão importantes como as palavras. Basta ver, por exemplo, os longos momentos de silêncio, praticamente inevitáveis quando se está a recapitular memórias profundamente

${ }^{12}$ Sigo aqui aspectos das minhas notas em Ribeiro, 2014. 
traumáticas, mas que, do ponto de vista do entrevistador, inevitavelmente põem em questão a credibilidade do requerente ao estatuto de refugiado. Quebrar o silêncio permitiria a essa pessoa adquirir uma identidade social, superar a condição de vítima, de simples objecto da violência, e afirmar um acto de autoria como reinscrição no universo do discurso. Nas condições do centro de detenção retratado por Melgar, isto, no entanto, só muito dificilmente se torna possível.

A recusa do reconhecimento significa a recusa de traduzir. A persistência de representações coloniais do outro neste contexto é uma evidência: os refugiados e migrantes provêm do Sul global e são vítimas de processos políticos e de conflitos armados que, sob o regime colonial de representação, são imaginados como típicos de uma condição endémica de caos incivilizado. Uma ética da tradução, pelo contrário, tem de conduzir a uma posição muito diferente, com consequências importantes, entre as quais é de sublinhar, de novo, a seguinte, associada ao poder transformador da tradução: a tradução não é nunca um processo unidireccional, mas sim um processo no curso do qual ambos os termos da relação são postos em movimento e, como assinalei atrás, são levados a rever e pôr em questão os seus respectivos quadros de referência. É uma relação de reciprocidade, o que significa que lidar com o chamado "problema dos refugiados" não pode ser simplesmente visto como um problema de integração, tem de implicar a disponibilidade das sociedades de acolhimento para um empenhamento na construção de quadros mentais e estruturas sociais verdadeiramente multiculturais. Na sua obra The Search for the Perfect Language, Umberto Eco escreve que "a Europa poliglota não será um continente em que os indivíduos se relacionam fluentemente em todas as outras línguas; no melhor dos casos, poderia ser um continente em que as pessoas podem encontrar-se e falar umas com as outras, cada qual na sua língua, compreendendo, o melhor que puderem, o discurso dos outros" (Eco, 1995: 351). Talvez que este padrão de incompletude mútua e de imperfeição, combinado com a capacidade de construir uma zona de tradução comum, possa, na sua ambição prudente, proporcionar um modelo de relações e práticas sociais conscientes da necessidade permanente de traduzir e de ser traduzido como base fundamental de qualquer comunidade humana.

\section{Referências bibliográficas}

Appiah, Kwame Anthony (1993), "Thick Translation”, Callaloo, 16(4), 808-819.

Apter, Emily (2006), The Translation Zone: A New Comparative Literature. Princeton:

Princeton University Press. 
Arendt, Hannah (1994), "We Refugees”, in Marc Robinson (org.), Altogether Elsewhere: Writers on Exile. Boston/London: Faber and Faber, 110-119 [orig. 1943].

Bauman, Zygmunt (2016), Strangers at Our Door. London: Polity Press.

Blanchard, Pascal; Bancel, Nicolas; Lemaire, Sandrine (orgs.) (2005), La fracture coloniale: la société française au prisme de l'béritage colonial. Paris: La Découverte.

Buden, Boris; Nowotny, Stefan; Simon, Sherry; Crinin, Michael (2009), "Cultural Translation: An Introduction to the Problem, and Responses”, Translation Studies, 2(2), 196-219.

Budick, Sanford; Iser, Wolfgang (orgs.) (1996), The Translatability of Cultures: Figurations of the Space Between. Stanford: Stanford University Press.

Cassin, Barbara (org.) (2004), Vocabulaire européen des philosophies: dictionnaire des intraduisibles. Paris: Seuil.

Chakrabarty, Dipesh (2000), Provincializing Europe: Postcolonial Thought and Historical Difference. Princeton: Princeton University Press.

Clifford, James (1986), "Introduction: Partial Truths", in James Clifford; George Marcus (orgs.), Writing Culture: The Poetics and Politics of Ethnography. Berkeley: University of California Press, 1-26.

Eco, Umberto (1995), The Search for the Perfect Language. Oxford: Blackwell.

Ervedosa, Clara (2017), "The Calibanisation of the South in the German Public 'Euro Crisis' Discourse”, Postcolonial Studies, 20(2), 137-162.

Forst, Rainer (2013), Toleration in Conflict: Past and Present. Cambridge: Cambridge University Press.

Habermas, Jürgen; Derrida, Jacques (2003a), "Unsere Erneuerung. Nach dem Krieg: Die Wiedergeburt Europas”, Frankfurter Allgemeine Zeitung, 31 de Maio.

Habermas, Jürgen; Derrida, Jacques (2003b), "February 15, or what Binds Europeans Together: A Plea for a Common Foreign Policy, Beginning at the Core of Europe”, Constellations, 10(3), 292-297.

Hall, Stuart (1992), “The Question of Cultural Identity”, in Stuart Hall; David Held; Tony McGrew (orgs.), Modernity and Its Futures. London: Polity Press, 273-325.

Honneth, Axel (2004), "Recognition and Justice: Outline of a Plural Theory of Justice”, Acta Sociologica, 47(4), 351-364.

Huntington, Samuel P. (1996), The Clash of Civilizations and the Remaking of the World Order. New York: Simon \& Schuster.

Iser, Wolfgang (1994), “On Translatability”, Surfaces, 4. Consultado a 03.07.2004, em https://www.pum.umontreal.ca/revues/surfaces/vol4/iser.html.

Jones, Reece (2016), Violent Borders: Refugees and the Right to Move. London/New York: Verso.

Large, Duncan; Akashi, Motoko; Józwikowska, Wanda; Rose, Emily (orgs.) (2018), Untranslatability: Interdisciplinary Perspectives. New York: Routledge. 
Levine, Suzanne Jill; Lateef-Jan, Katie (orgs.) (2018), Untranslatability Goes Global. New York/London: Routledge.

Maitland, Sarah (2017), What is Cultural Translation? London/New York: Bloomsbury Academic.

Meyer, Thomas (1997), Identitäts-Wabn. Die Politisierung des kulturellen Unterschieds. Berlin: Aufbau.

Pedra, Cláudia (2018), “Os refugiados climáticos terão direito a estatuto?”, Público, 3 de Setembro, p. 5.

Quijano, Aníbal (1997), “Colonialidad del poder, cultura y conocimiento en America Latina”, Anuario Mariateguiano, 9(9), 113-121.

Ribeiro, António Sousa (2004), “Os limites da tolerância: as 'lições' do Holocausto”, Revista de História das Ideias, 25, 405-421.

Ribeiro, António Sousa (2005), “A tradução como metáfora da contemporaneidade. Pós-colonialismo, fronteiras e identidades”, in Ana Gabriela Macedo; Maria Eduarda Keating (orgs.), Colóquio de outono. Estudos de tradução. Estudos póscoloniais. Braga: Universidade do Minho/Centro de Estudos Humanísticos, 77-87.

Ribeiro, António Sousa (2014), "Fronteiras intransponíveis. Notas sobre La forteresse, de Fernand Melgar", Revista Crítica de Ciências Sociais, 105, 153-158.

Santos, Boaventura de Sousa (2002), "Entre Prospero e Caliban: colonialismo, pós-colonialismo e inter-identidade”, in Maria Irene Ramalho; António Sousa Ribeiro (orgs.), Entre ser e estar: raizes, percursos e discursos da identidade. Porto: Edições Afrontamento, 23-85.

Santos, Boaventura de Sousa (2007), "Para além do pensamento abissal: das linhas globais à ecologia de saberes”, Revista Crítica de Ciências Sociais, 78, 3-46.

Stora, Benjamin (1999), Le transfert d'une mémoire: de l'Algérie française au racisme anti-arabe. Paris: La Découverte.

Todorova, Maria (1997), Imagining the Balkans. New York: Oxford University Press. Venuti, Lawrence (1998), The Scandals of Translation: Towards an Ethics of Difference. London: Routledge.

Wodak, Ruth; Cillia, Rudolf de; Reisigl, Martin; Liebhart, Karin; Hofstätter, Klaus; Kargl, Maria (1998), Zur diskursiven Konstruktion der nationalen Identität. Frankfurt am Main: Suhrkamp.

Wodak, Ruth (2013), "Europäische Identitäten. Nationalismen und (Sprach-) Barrieren. Festrede zur Eröffnung des Internationalen Brucknerfestes Linz 2013”. Consultado a 24.08.2018, em https://medienportal.univie.ac.at/uploads/media/ FestvortragLinzWodakshort2.pdf.

Wodak, Ruth (2018), "Discourses about Nationalism”, in John Flowerdew; John E. Richardson (orgs.), The Routledge Handbook of Critical Discourse Studies. New York: Routledge, 403-420. 


\section{António Sousa Ribeiro}

Faculdade de Letras da Universidade de Coimbra | Centro de Estudos Sociais da Universidade de Coimbra

Largo da Porta Férrea, 3004-530 Coimbra, Portugal

Contacto: asr@ces.uc.pt

\section{To Translate and Be Translated.} Notes on Discourse and Migrations

This article examines some of the relationships between discourse and migrations, highlighting how regimes of representations of a colonial origin persist in contemporary Europe, defining the essential vectors of an ethics and politics of translation that may provide the foundations for a logic of inter-recognition.

Keywords: coloniality; discourse; migrations; refugees; translation.

\section{Traduire et être traduit. Notes sur le discours et les migrations}

Dans cet article nous nous penchons sur quelques aspects de la relation entre discours et migrations, en mettant en exergue la persistance, dans l'Europe contemporaine, de régimes de représentation aux racines coloniales et en définissant les vecteurs essentiels d'une éthique et d'une politique de la traduction susceptibles de fournir les fondements d'une logique de reconnaissance mutuelle.

Mots-clés: colonialité; discours; migrations; réfugiés; traduction. 